\title{
Inclusão excludente e exclusão includente: estudos sobre a ralé em um clube social
}

\author{
Fernando Ressetti Pinheiro Marques Vianna ${ }^{1}$ \\ FRANCIS KANASHIRO MENEGHETTI ${ }^{2}$ \\ Juliana Previatto Baltini TONON ${ }^{3}$ \\ LEONARDO TONON ${ }^{2}$
}

\author{
1 Fundação Getulio Vargas (FGV EAESP) / Escola de AdMinistração de EMPresas de SÃo PaUlo, SÃo PAULO - SP, BRASIL \\ 2 Universidade Tecnológica Federal do Paraná (UTFPR) / Programa de Pós-Graduação em Administração, CURITIBA - PR, BRASIL

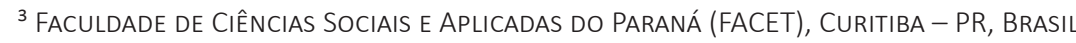

\begin{abstract}
Resumo
Este artigo foi motivado por situações de exclusão social de determinados grupos em um clube social no Sul do Brasil. Por meio de estudo etnográfico, buscou-se analisar de que modo a ralé é socialmente excluída de determinadas situações e incluída em outras e por qual motivo. Situações sociais, muitas vezes de ordem simbólica, como o uso de uniformes, a existência de uma "senzala" para os funcionários e a não relação entre sócios e funcionários, entre outras, possibilitaram que o movimento dialético entre o excluir e o incluir fosse explorado. É nesse contexto que se discute a exclusão includente e a inclusão excludente. Tal processo resulta na manutenção da desigualdade social por meio de práticas aparentemente normais, justificáveis, institucionalmente aceitas e incentivadas. Para a ralé, porém, que é incluída e/ou excluída por meio dessas práticas, as consequências são a reprodução e a legitimação de sua condição de precariedade.
\end{abstract}

Palavras-chave: Inclusão excludente. Exclusão includente. Clube social. Etnografia.

\section{Exclusionary inclusion and inclusive exclusion: studies on harassment at a members club}

\begin{abstract}
This article was motivated by situations of social exclusion of certain groups at a members club in southern Brazil. Through an ethnographic study, we sought to analyze how marginalized populations are socially excluded from certain situations and included in others, and why. Social situations are often symbolic, such as the wearing of uniforms, the existence of a "senzala" for employees, the non-relationship between members and employees, among others, allowed us to explore the dialectical movement between exclusion and inclusion. It is in this context that inclusive exclusion and exclusionary inclusion are discussed. This process results in the maintenance of social inequality through seemingly normal, justifiable, institutionally accepted, and encouraged practices. For marginalized populations included and / or excluded through these practices, the consequences are the reproduction and legitimation of this precarious condition.
\end{abstract}

Keywords: Inclusive exclusion. Exclusionary inclusion. Social club. Ethnography.

\section{Inclusión excluyente y exclusión incluyente: estudios sobre la clase baja en un club social}

\section{Resumen}

Este artículo fue motivado por situaciones de exclusión social de ciertos grupos en un club social en el sur de Brasil. A través de un estudio etnográfico, buscamos analizar cómo la clase baja es socialmente excluida de ciertas situaciones e incluida en otras, y por qué motivo. Las situaciones sociales, a menudo simbólicas, como el uso de uniformes, la existencia de "dependencias de empleados", la no relación entre socios y empleados, entre otros, nos permitieron explorar el movimiento dialéctico entre excluir e incluir. En este contexto discutimos la exclusión incluyente y la inclusión excluyente. Este proceso resulta en el mantenimiento de la desigualdad social a través de prácticas aparentemente normales, justificables, institucionalmente aceptadas y alentadas. Sin embargo, para la clase baja, que es incluida y/o excluida a través de estas prácticas, las consecuencias son la reproducción y legitimación de su condición precaria.

Palabras clave: Inclusión excluyente. Exclusión incluyente. Club social. Etnografía. 


\section{INTRODUÇÃO}

Um de vocês pegou a bota da minha filha!

Esta epígrafe foi a afirmação que motivou a escrita deste artigo - ela foi dita por uma convidada na festa junina de um clube social localizado no Sul do Brasil. A acusação foi direcionada a um membro da equipe de segurança da festa. Ao invés de reagir contra tal acusação, o segurança saiu rapidamente em busca do item roubado.

O segurança pode ser enquadrado como membro da ralé brasileira (SOUZA, 2017), termo provocativo utilizado por Jessé Souza para se referir a uma classe herdeira da tradição escravocrata no Brasil. Tal classe é fruto do abandono dos ex-escravos, sendo mantida e legitimada pelo argumento que culpa a corrupção e o Estado por sua situação, mas exime a elite e a classe média de suas considerações. Souza (2017) afirma que a chamada ralé não se relaciona a qualquer classificação econômica, mas ao seu aparato para competir no mundo. A desigualdade social evidenciada pela existência dessa ralé, que Freitas e Luna (2006) afirmam ser um problema a ser enfrentado pela sociedade brasileira, não parece ser um problema para os algozes contemporâneos, a classe média (SOUZA, 2017).

Quando a convidada da festa mencionada no primeiro parágrafo acusa o segurança, ela está legitimando a desigualdade social que ocorre com ações que excluem social, cultural e economicamente, e em várias outras esferas, os membros da ralé. O próprio segurança citado legitima a desigualdade que sofre quando não reage à acusação, pois o discurso hegemônico da meritocracia sempre aponta o fato de que ele estar ali é uma forma de inclusão, uma "oportunidade" de não ter se tornado um delinquente. Essa situação relatada evidencia o problema da desigualdade na inclusão do segurança em uma classe do não ser (MACIEL e GRILLO, 2009). A essa classe da ralé não cabe o desejo de ser médico ou doutor, mas apenas o esforço para não ser bandido.

Evidências da exclusão da ralé podem ser identificadas em outras publicações, como nas reportagens jornalísticas de Boere e Lima (2016) e Martín (2016), que exploraram o tema pelas lentes do preconceito e da humilhação sofridos por babás em um clube de elite no Rio de Janeiro. Essas mulheres não podiam sequer usar o banheiro feminino, pois "não tinham a mesma educação" que os sócios, de acordo com o relato de uma sócia do clube (BOERE e LIMA, 2016).

Com base nas duas situações relatadas, uma empírica vivida por um dos pesquisadores na festa do clube e outra relatada nas reportagens consultadas, buscou-se questionar:

- De que modo a ralé é excluída socialmente de determinadas situações e incluída em outras?

- Quais motivos levam a essas formas de exclusão e/ou inclusão?

Embora diferentes estudos abordem a exclusão social de determinados grupos (MEDEIROS e MACÊDO, 2006; SOUZA, 2009; CARVALHO-FREITAS e MARQUES, 2010), este artigo justifica seu desenvolvimento por explorar o movimento entre o excluir e o incluir como um processo que resulta na manutenção da desigualdade social. O desenvolvimento do trabalho em um clube elitista torna a pesquisa ainda mais rica sob o ponto de visa empírico. Isso porque apresenta a dialética exclusão/inclusão em práticas aparentemente normais, justificáveis, institucionalmente aceitas e incentivadas. No entanto, para o outro lado, que é incluído e/ou excluído por meio das práticas, as consequências são a reprodução e a legitimação de sua condição de precariedade desde os tempos coloniais.

Quanto à relação deste artigo com os estudos organizacionais, primeiro atentamos ao fato de que ele é permeado por outras áreas de pesquisa, como a sociologia, a psicologia e a antropologia (MATITZ e VIZEU, 2012). Em seguida, acreditamos que os aspectos aqui expostos relativos às formas como a organização expressa seu management se afastam das justificativas modernas e apresentam pontos próximos à construção dos estudos organizacionais no Brasil (PAULA, MARANHÃO, BARRETO et al., 2010; DJELIC, 2016).

Dentro da área em questão, o tema exclusão social conta com importantes trabalhos relativos a cidades e espaços (GONÇALVES, PAIVA, BARBOSA et al., 2009; BENTO, ROJAS, LEMOS et al., 2016; SILVA, LIMA e NELSON, 2016), mas esta pesquisa levanta outra perspectiva, com o auxílio da sociologia. Os trabalhos recentes de Jessé de Souza e os escritos já consagrados de José de Souza Martins são aqui utilizados, sem precedentes nos estudos organizacionais e na administração até o momento, com o objetivo de apresentar um conjunto (ou combinado) de práticas de gestão que reafirmam uma exclusão existente desde que o Brasil é Brasil, afastadas das questões puramente econômicas (MARTINS, 1997). 
Assim, para explorar mais situações como a relatada no primeiro parágrafo deste artigo, passamos a tratar como objeto de estudo as situações sociais geradas pelas interações entre os sócios e os funcionários de um clube de classe média, mas elitista, no Sul do Brasil.

Seguindo a orientação de Spradley (2016) para o desenvolvimento de estudos etnográficos, a observação de situações sociais se dá por meio do acompanhamento das atividades que geram tais situações. Assim, as observações ocorreram principalmente na academia do clube, mas também se ampliaram em alguns momentos para outras atividades que constituíram oportunidades para aprofundar o trabalho, como ambientes de recreação, alimentação e outros eventos do próprio clube. Ao longo da pesquisa, pôde-se contatar alguns funcionários em conversas informais, porém, muito ricas.

A pesquisa foi realizada entre os meses de agosto e dezembro de 2018. A frequência média das observações foi de 4 vezes por semana, no mínimo durante 1 hora por dia, em diferentes momentos. As anotações foram feitas no bloco de notas do telefone celular. A escolha de um smartphone se deu por possibilitar certo anonimato, na medida em que o uso de tais aparelhos é comum entre os frequentadores do local, não chamando atenção para o pesquisador e viabilizando que as notas fossem tomadas em tempo real. Posteriormente, as notas foram transcritas na forma de diários de campo, permitindo que algumas análises já fossem desenvolvidas no transcorrer da própria pesquisa.

Durante a pesquisa, pôde-se entrar em contato com diversos funcionários do clube, de diferentes hierarquias, bem como observá-los em suas funções e em suas relações com os sócios e entre si. Foram muitas conversas de curta ou média duração ao longo da pesquisa. Tais conversas enriqueceram as observações, pois, nas interações observadas, aquilo que era relatado ou informado foi corroborado ou confrontado.

Ao longo dessas conversas e observações se estabeleceu maior aproximação com uma das trabalhadoras. Desse modo, a principal participante, que trouxe informações-chave para o estudo, foi uma funcionária da limpeza, que trabalhava no local há oito anos e que, seguindo a orientação de Duarte (2002), não só pertence à organização, mas também faz parte da ralé brasileira. O nome verdadeiro dessa informante foi substituído, neste artigo, por Janaína, em alusão à personagem da música da banda Biquíni Cavadão, com o mesmo nome, sobre uma trabalhadora com sonhos, mas sem tempo para realizá-los.

A relação entre Janaína e o pesquisador ocorreu de modo similar à relação entre Foot-White (1995) e Doc, seu informantechave. Tal qual Doc, Janaína mudou a perspectiva do pesquisador a respeito dos funcionários do clube, bem como, a intimidade e o conhecimento adquiridos ao longo da pesquisa, influenciaram diretamente seu rumo. Vale mencionar que a citação do trabalho de Foot-White (1995) se mostra pertinente devido ao fato do autor contar apenas com um informante-chave, mas de significância e sensibilidade ímpares, assim como nesta pesquisa. Enquanto o pesquisador esteve na academia do clube na companhia de Janaína, outros funcionários se sentiram à vontade para conversar, como se Janaína, por sua presença, seu tempo de trabalho naquele local e seu respeito perante os colegas, desse seu aval. Apesar de, neste artigo, não se apresentarem outras falas além das de Janaína, as categorias aqui desenvolvidas e os rumos da pesquisa foram compostos por cada olhar, gesto e fala dos funcionários.

Este estudo apresenta em sua estrutura o conceito de exclusão social e, em seguida, o conceito de inclusão social, assim como a relação dicotômica e até dialética desses dois conceitos, já que são termos relacionados (SAWAIA, 1999; RAWAL, 2008). Em seguida são apresentados os resultados das observações da pesquisa, para viabilizar a análise dos modos de exclusão e inclusão da ralé que trabalha no clube, a partir dos conceitos de exclusão includente e inclusão excludente. Por fim, apresentam-se as análises que buscam responder aos questionamentos apresentados.

\section{EXCLUSÃO/INCLUSÃO: TENSIONAMENTOS EXISTENTES E POSSÍVEIS}

Inicialmente, sobre o tema exclusão, o primeiro aspecto analisado se relaciona ao surgimento do termo, que conta com uma literatura coesa e ampla em relação à sua aplicação. Para Rawal (2008), o termo exclusão é utilizado em diferentes países e para designar diferentes formas de exclusão, de acordo com a unidade de pesquisa adotada por um ou outro autor.

O segundo aspecto a ser analisado quanto ao termo exclusão parte da insuficiência da dimensão econômica para justificar os excluídos. Segundo Martins (1997), Cannan (1997) e Haan (2000), os indivíduos não são mais excluídos apenas por não trabalharem, mas por fazerem parte de inúmeras minorias excluídas. 
O terceiro aspecto aqui abordado quanto ao termo exclusão diz respeito ao seu uso na realidade brasileira, que constitui o foco deste estudo. Neste último aspecto, diversos autores apresentam a exclusão como parte da dialética exclusão/inclusão, em um processo que inclui os indivíduos em situações precarizadas e silencia a exclusão (MARTINS, 1997; SAWAIA, 1999; VERAS, 1999; NASCIMENTO, 2006). Cabe mencionar que esse bojo teórico nos leva a esclarecer que a dialética exclusão/ inclusão é encarada como algo proposital, tornando-se fundamental para a etapa seguinte do trabalho, que apresenta, de modo sistemático, situações observadas de exclusão social e inclusão social.

Haan (2000) e Wanderley (1999) afirmam que o termo exclusão social foi cunhado em 1974 por Rene Lenoir, então Secretário de Ação Social da França. Lenoir associou a exclusão a fatores como processos acelerados e desorganizados de urbanização, desigualdade de renda e inadaptação e uniformização do sistema escolar. Tal exclusão era sentida por indivíduos pobres e desempregados, que eram atendidos por instituições criadas para apoiá-los.

Contudo, a partir de observações do trabalho dessas mesmas instituições de apoio, Cannan (1997) e Haan (2000) relatam que foram percebidos outros grupos buscando auxílio, como doentes mentais, idosos e imigrantes. De acordo com Rawal (2008) e Aasland e Fløtten (2014), a ampliação do número de grupos de indivíduos incluídos no rol de excluídos evidencia que a exclusão decorre de diferentes fatores. Nesse sentido, os autores elencam as exclusões nas ordens sociais, econômicas, culturais e políticas.

Martins (1997) afirma que há, também, a ampliação e transformação dos termos utilizados para descrever grupos de excluídos, como pobres e marginais, e que a insuficiência de termos denota seu número cada vez maior. Com o aumento dos grupos de excluídos e das formas de exclusão, esse termo passa a abarcar diferentes significados, que vão desde a "concepção de desigualdade como resultante de deficiência ou inadaptação individual até a injustiça e exploração social” (SAWAIA, 1999, p. 7).

O aumento de grupos excluídos é atribuído por Wanderley (1999) e Nascimento (2006) à crise do modelo de gestão social. De acordo com os autores, essa crise resultou na fragilização da proteção social e na fragmentação da coesão social, constituídas ao longo do século XIX. A fragilização e fragmentação desvalorizam a solidariedade e hipervalorizam as relações econômicas. Para Martins (1997) discussões sobre exclusão, muitas vezes, reduzem o problema ao resultado, ao passo que o problema se encontra no processo. Para o autor, o termo exclusão remete ao movimento que empurra os pobres e fracos para fora de situações justas e concretas ou, ainda, expulsa-os de certas relações sociais.

No Brasil, Veras (1999) e Safatle (2017) relatam que a eliminação de qualquer prática de assistência aos excluídos tem forte relação com o discurso neoliberal no âmbito econômico, que embasa novas formas de sujeições sociais em um movimento semelhante ao apartheid entre as classes. Contudo, Souza (2017) esclarece que o discurso econômico é adotado estrategicamente como modo de evitar que a discussão da desigualdade avance sobre o campo social e seus privilégios. Dessa forma, Nascimento (2006) afasta a hipótese do excluído sê-lo devido a alguma transgressão cometida por si ou por seu grupo. Para o autor, a exclusão é uma imputação exterior, do dominante sobre o dominado, que tem suas origens no Brasil colonial e na exclusão de índios e negros por alguns povos europeus.

Veras (1999) e Nascimento (2006) afirmam, ainda, que a fragilização do apoio social repercute de duas formas: a) erguendo barreiras à produção de uma sociedade igualitária; e b) oferecendo aos excluídos um vasto menu de dimensões geradoras de exclusão. Tais dimensões vão desde a instabilidade conjugal e inadequação da vida familiar e social até a inexistente participação em atividades sociais.

De acordo com Honneth (2003), os fatores que geram a exclusão passam a ser dimensões sistemáticas de desrespeito. No entanto, segundo Veras (1999), o sujeito excluído socialmente não pode reclamar e, muitas vezes, sequer se percebe como excluído. Isso ocorre por tal sujeito ser incluído na dimensão de não cidadão da comunidade capitalista, ou seja, é um sujeito capaz de consumir bens e serviços, mas, na maioria das vezes, tem seus direitos ceifados pelos grupos dominantes (VERAS, 1999; NASCIMENTO, 2006).

Nesse sentido, para Veras (1999) e Debord (1991), o desconhecimento de seus direitos e a não percepção de sua exclusão por parte do sujeito excluído decorrem de fatores socialmente compartilhados, dentre eles o fato de vivermos em uma sociedade de imitação, de reprodutibilidade e de vulgarização, em vez de uma sociedade voltada à criação e ao sonho. Dessa forma, aquilo que o sujeito desconhecido pensa estar realizando quando consome, é um momento em vão, uma espécie de falso-verdadeiro. Esse movimento serve como forma de retirar o foco do trabalhador da fábrica na exploração que sofre naquele ambiente, sobrepondo uma sociedade do consumo à sociedade da produção (MARTINS, 1997). 
Castel (1998) afirma, ainda, que a hipervalorização do trabalho, como principal ferramenta de consumo e inclusão, também gera uma hiperdesvalorização do não trabalho. Nesse cenário, o não trabalho primeiro exclui e, em seguida, resulta em um novo modelo de trabalho baseado no desespero de um cidadão pertencente à ralé e sem qualificação - um trabalhador que se sujeita a qualquer condição para se ver incluído. Tendo em vista que no discurso meritocrata da classe média o insucesso da ralé é resultado de seu próprio fracasso, e não de um fracasso político e social (HONNETH, 2003), esse indivíduo da ralé aceita a flexibilidade (SENNETT, 1999) como uma dádiva e é excluído do trabalho adequado para ser incluído em formas precárias de trabalho (KUENZER, 2002).

Segundo Martins (1997), falar de exclusão reduz o problema a um resultado, ao passo que o problema se encontra no processo. Para o autor, o termo exclusão remete ao movimento que empurra os pobres e os fracos para fora de situações justas e concretas e, ainda, das relações sociais. Contudo, não é possível tratar exclusão e inclusão isoladamente, mas como um fenômeno que Sawaia (1999) e Rawal (2008) denominam dialética da inclusão/exclusão, com os termos relacionados e dependentes. Para Sawaia (1999), tal dialética é fomentada para apresentar o incluído como um privilegiado e bem assistido e o excluído como um marginalizado. Muitas vezes, o excluído não se sente excluído, mas privado, sendo, dessa forma, incluído em uma categoria que sofre privações (MARTINS, 1997).

Ao analisar o caso brasileiro, percebemos que a ralé é parte incluída no discurso meritocrático da classe média privilegiada, que valoriza o esforço como modo de alcançar reconhecimento financeiro e social (SOUZA, 2017), mas é excluída das benesses do mesmo discurso. Para Sawaia (1999) e Maciel e Grillo (2009), essa exclusão ocorre quando a ralé não alcança os mesmos resultados que a classe média privilegiada, e é estrategicamente legitimada quando a culpa recai sobre a própria ralé e sua suposta falta de vontade e esforço. Esse movimento é descrito por Veras (1999) como uma tensão entre o empurrar para dentro e o empurrar para fora um mesmo grupo de pessoas, com o objetivo de deixá-lo sem qualquer possibilidade de ação contrária.

O uso do termo inclusão, quando aplicado a algum aspecto da ralé é, com frequência, problemático, já que a inclusão não é opcional, mas apresentada como a melhor solução para um indivíduo fugir da exclusão. Esse fato é relatado por Maciel e Grillo (2009) quanto à inclusão de indivíduos da ralé em um grupo de trabalhadores uniformizados, que veem nesse tipo de inclusão a única solução para se afastar da delinquência e das revistas policiais. Trata-se de um modo de salvação de sua condição de excluído, mas que pode estar relacionado com sua participação em um grupo explorado e cerceado (RAWAL, 2008).

De acordo com Maciel e Grillo (2009), a ralé se vê incluída em grupo, mesmo com seu foco de vida sendo balizado pela capacidade de consumo e desenvolvimento econômico, características da reprodução do pensamento neoliberal da classe média e da elite. No entanto, a dignidade não está incluída, apenas um salário camuflado pela ilusão de uma inclusão pelo consumo. Esse modelo de pensar é necessário para a reprodução das bases ideológicas e sociais do capitalismo (MARTINS, 1978).

Essa inclusão também é evidenciada por outros símbolos que vão além do consumo. Jodelet (1999) afirma que a categorização sistemática, atribuindo os mesmos uniformes, funções e punições semelhantes aos grupos, faz com que estes desenvolvam uma noção de inclusão. A autora afirma, ainda, que os indivíduos incluídos em grupos dominantes carregam mais características individuais e exercem a individualidade, enquanto os grupos dominados se percebem como homogêneos e as características individuais acabam sendo, muitas vezes, as características do grupo.

Segundo Paugam (1999), a inclusão da ralé em grupos específicos, inclusive quando há camuflagem da boa intenção, é limitada, já que o próprio assistencialismo busca manter este grupo de pessoas na marginalidade. Dessa forma, podemos afirmar que a inclusão da ralé dominada em determinado grupo ou categoria só ocorre para facilitar sua exclusão. Trata-se de uma ralé vestida com seus uniformes de não consumidores para facilitar sua identificação e vigilância (CELEGUIM e ROESLER, 2009).

Kuenzer (2002) apresentou os conceitos de exclusão e inclusão de modo interligado, como elementos que não se dissociam, criando os termos exclusão includente e inclusão excludente. O primeiro termo, exclusão includente, esclarece que as pessoas pertencentes às classes privilegiadas negativamente são excluídas de uma condição estável de trabalho, para serem incluídas em uma condição precarizada de trabalho. Inclusão excludente, por sua vez, representa o processo de inclusão de uma parcela da população na educação tecnicista, como modo de excluir a possibilidade de desenvolver pensamento crítico. Devemos salientar que, a partir de uma reinterpretação de Kuenzer (2002), esses termos serão fundamentais para o desenvolvimento do argumento aqui proposto. 


\title{
A INCLUSÃO EXCLUDENTE E A EXCLUSÃO INCLUDENTE: AS VIVÊNCIAS DE JANAÍNA E SEU TRABALHO NO CLUBE
}

\author{
Janaína acorda todo dia às quatro e meia \\ E já na hora de ir pra cama, Janaína pensa \\ Que o dia não passou, que nada aconteceu [...] \\ Mas ela diz \\ Que apesar de tudo ela tem sonhos
}

(Bruno Gouveia, interpretado por Biquini Cavadão)

Para tensionar os elementos includentes e excludentes das práticas organizacionais, buscamos, nesta etapa do estudo, avaliar as ocasiões nas quais os funcionários do clube, ou a ralé (SOUZA, 2017), passam por situações sistemáticas atinentes à sua precarizada categoria social. A partir dessa constatação, os termos exclusão includente e inclusão excludente (KUENZER, 2002) serão utilizados e (re)interpretados aqui como forma de explicar os fenômenos observados na dinâmica do clube.

Assim, as situações observadas e relatadas no clube são apresentadas como formas estruturadas de legitimação, reprodução e manutenção dessa desigualdade social. Não é problema e faz parte da consciência social, de normas justificáveis e institucionalmente incentivadas, que exclusão e inclusão da categoria social precarizada sejam vivenciadas e reproduzidas quando dos interesses da elite e da classe média.

Janaína sentiu a exclusão no abandono daquele local pelo qual tinha uma estima quando entrou, mas que, de acordo com Honneth (2003) passou a ser símbolo de sofrimento:

Todo mundo falava: 'nossa, tá trabalhando no clube', e eu me achava um pouco mesmo. Mas depois de um tempo, você descobre como é, e não se sente mais valorizada.

Os relatos se iniciam pelo uniforme recebido por Janaína ao começar a trabalhar no clube, feito de tecido barato e com aparência de usado, já que é o uniforme da categoria que ocupa a base hierárquica dos trabalhadores daquela organização os funcionários da limpeza. Trata-se do primeiro elemento que inclui excluindo. Tal uniforme, apesar de representar a inclusão do indivíduo em seu quadro de funcionários, tem o objetivo de excluir esses funcionários de qualquer interação social com os sócios ou mesmo com outros funcionários. Isso é notado em algumas observações quando, ao longo de 10 minutos, Janaína permanece na entrada do pavimento da academia do clube e cerca de 20 sócios passam por ela, mas nenhum a cumprimenta, mesmo quando olham para ela.

A contratação do indivíduo pelo clube inclui o funcionário em um grupo uniformizado, vigiado, e parte de um grupo de indivíduos esforçados. No entanto, os uniformes, camuflados na boa intenção do funcionário não gastar sua roupa para trabalhar e fazer parte de um grupo (PAUGAM, 1999), funcionam como modo de homogeneizar os indivíduos. Esse grupo, aos olhos dos sócios e da sociedade que ali transita, é inferior quanto à capacidade de consumo e representa indivíduos desqualificados (CELEGUIM e ROESLER, 2009; SOUZA, 2017).

Essas afirmações são respaldadas pelo fato de nem todos os funcionários usarem uniformes dentro do clube. A diretoria, formada por sócios que ocupam cargos estratégicos, não usa uniforme, pois faz parte de uma classe privilegiada e detentora do conhecimento (SOUZA, 2017). Tal diretoria é o grupo dominante que Jodelet (1999) afirma ter maior individualidade, pois suas funções são exercidas usando "roupas de marca". Os gerentes também não usam uniformes, pois tampouco se caracterizam como ralé, trata-se de uma classe média que Souza (2017) classifica como capatazes da elite. A esses gerentes são conferidas regalias por parte da diretoria, seus senhores, como negociar quais empresas podem e quais não podem prestar serviços ao clube (FREYRE, 2003; SOUZA, 2017).

A mesma ausência de uniforme que representa um status nos níveis estratégicos e gerenciais é punida no caso da ralé. Janaína relata:

[...] esses dias eu tava com uma blusa diferente, porque tava frio, né? Já veio o Seu Fulano [gerente geral do clube] perguntar se eu não tinha uniforme. A minha supervisora sempre fala que isso ainda vai dar advertência. 
E ela apresenta outra situação, relativa ao calçado:

Eu comprei um tênis melhor [ergonomicamente do que o calçado oferecido pelo clube para o trabalho], só que é vermelho. Porque tenho dor nas costas de ficar de pé o dia todo. Disseram que tem que ser preto, igual ao do uniforme. E agora, se eu quiser outro, eu que tenho que comprar.

À dor nas costas relatada por Janaína relacionamos outra situação social: a vigilância do ambiente panoptizado (BENTHAM, 2013) da academia do clube conta com 15 câmeras vigiando um vão de $200 \mathrm{~m}^{2}$. Aparentemente não há outro objetivo nessa vigilância que não seja estabelecer a ordem e agrupar os desiguais, coercitivamente, em um conjunto de indivíduos (FOUCAULT, 2003).

Isso fica claro quando, nas conversas com o pesquisador, Janaína disfarça com utensílios de limpeza em mãos e limpa incessantemente os aparelhos da academia próximos a ele, mesmo que sem uso desde a última limpeza. Além disso, reforça a ideia de que não deve haver interação social entre funcionários e sócios. Apesar de não haver uma regra escrita que impeça um funcionário de conversar com um sócio, nas palavras de Martins (1999), há o embaraço do decoro. Tal embaraço se encontra nos costumes e na construção social do clube, que instrui informalmente tanto sócios quanto funcionários a não terem qualquer intimidade.

Essa intimidade proibida ou, nas palavras de Martins (1999), a quebra do decoro, evidencia-se no relato de Janaína, quando ela conta que teve sua atenção chamada pelos chefes devido à reclamação de uma sócia que alegou não conseguir se concentrar em seu treino na academia, devido ao fato de Janaína estar conversando com uma sócia.

A vigia também funciona como modo de mostrar aos funcionários que o trabalhar no clube significa não descansar, mesmo que o trabalho esteja feito. Os incluídos, aqui, são excluídos das rotinas de trabalho com descanso, com benefícios por produtividade ou com jornadas de trabalho adequadas. Observamos várias vezes em que a academia, mesmo vazia, era incessantemente limpa pelas funcionárias. Tal comportamento é esclarecido na fala de Janaína: "sentar, então, não podemos mesmo, são doze horas de pé..." e ela afirma que "tem que rodar", esclarecendo que as funcionárias da limpeza sempre precisam parecer que estão limpando ou sofrerão sanções.

E se Janaína e seus pares não podem conversar com sócios, quiçá almoçar perto deles. Ao longo das observações, verificamos a existência de um local fora do clube, do outro lado da rua, para o qual os funcionários se dirigiam periodicamente. Quando questionada sobre esse local, Janaína relatou que se tratava de um local denominado associação, espaço legitimado pelo clube inicialmente voltado aos funcionários para confraternizar, mas é utilizado efetivamente como refeitório, vestiário e espaço para que os funcionários deixem seus pertences antes de entrar no clube. Vale ressaltar que fazer parte da associação demanda um pagamento mensal por parte dos funcionários.

Caracterizamos a ralé como uma classe escravocrata, recorrendo às palavras de Souza (2017), então, é possível categorizar a associação como sua senzala. Esta se refere a um local de legitimação de desigualdade social, no qual o clube deposita homens e mulheres, "brancxs", "negrxs", "pardxs" e "mulatxs", sem distinção de gênero ou raça/etnia, mas com a distinção exclusiva de uma raça social que usa uniforme. Naquele local, os funcionários são excluídos do espaço social do clube para ser incluídos em um grupo que pertence à mesma classe uniformizada e que come a mesma comida. Pode-se afirmar que a refeição oferecida aos funcionários os inclui em uma condição ainda pior, já que, nas palavras de Janaína,

\section{[...] a comida é horrível, eu até já trago comida de casa, porque meu estômago não aguenta mais aquilo.}

A partir de Jodelet (1999) e Celeguim e Roesler (2009), podemos afirmar que a categorização pelos uniformes e a associação inicialmente criariam, de modo simbólico, uma noção de inclusão. Cabe destacar, porém, que, por meio de observações, percebeu-se que na associação todas as relações vivenciadas dentro do clube são reproduzidas. Ali, lugar destinado à interação entre os funcionários, os grupos não se misturam e continuam reproduzindo as ações do clube e excluindo-se pelos uniformes que vestem.

A TV do clube foi outra situação social observada nesta pesquisa. O clube conta com televisões espalhadas em diferentes pontos de sua estrutura. Tais televisões repetem, incessantemente, como o Grande Irmão de Orwell (2009), propagandas de produtos e serviços feitos para os sócios e programas que apresentam esses sócios como dedicados, esforçados, vencedores e merecedores de sua posição social. É a meritocracia, na qual a classe excluída não tem voz ou vez. 
Dessa forma, os funcionários percebem que estão excluídos daquele grupo de vencedores que compra produtos e serviços exclusivos, com os frutos de seus esforços. Assim, os funcionários se inserem na categoria que hipervaloriza o esforço e a dádiva do trabalho remunerado como modo de consumir aquilo que é apresentado em um espetáculo falso-verdadeiro do consumo (DEBORD, 1991; CASTEL, 1998; VERAS, 1999). Essas formas de exclusão são estruturalmente pensadas para reproduzir as bases ideológicas e sociais do capitalismo (MACIEL e GRILLO, 2009).

Eventos sociais promovidos pelo clube (festas e bazar dos funcionários) ou atitudes de alguns sócios, apresentados na sequência, se relacionam à inclusão excludente e vão ao encontro da manutenção da desigualdade pelo assistencialismo mencionada por Paugam (1999).

Uma vez ao ano o clube fecha suas portas aos sócios para proporcionar aos funcionários um dia para que eles "aproveitem" o clube com suas famílias. Para Carneiro e Rocha (2009), essas festas trazem à mesa o empregado doméstico como uma forma de reafirmar que ele sempre deve estar a postos. A festa ocorre sob a vigilância de câmeras, gerentes e diretores e tem um duplo objetivo em relação à manutenção da desigualdade social: a) o primeiro motivo se relaciona ao sucesso que aquele indivíduo apresenta para a família, por estar incluído em um ambiente suntuoso, regado a piscinas e lazer, estando, assim, excluído de um destino quase certo de delinquência; e b) o segundo motivo tem relação com o primeiro e com o que Maciel e Grillo (2009) afirmam acontecer entre os membros da ralé que é o funcionário, ao levar seus filhos até a festa para que eles vejam o trabalho do pai e já se familiarizem com suas futuras, e únicas, oportunidades de ser servos da classe média.

O bazar dos funcionários também chama atenção, na medida em que o clube incentiva os sócios a doarem roupas, utensílios e eletrodomésticos para um bazar montado com o propósito de que os funcionários possam escolher para si, aquilo que não serve mais para os sócios. A partir de Carneiro e Rocha (2009), entende-se que esse tipo de mimo só serve para que a ralé não deseje a vida do sócio, pois já tem um pedacinho dela.

Esse pedacinho da vida do sócio que deve saciar o apetite da ralé também é evidenciado na fala de Janaína, quando ela relata que, com seu esforço, já conseguiu comprar um sobrado na região metropolitana da capital em que se localiza o clube, em uma das regiões mais violentas do estado, mas que "é em condomínio fechado e tem churrasqueira". Esses detalhes foram enfatizados mais de uma vez por Janaína em diferentes conversas, pois isso, para ela, aproxima-a daqueles que ela serve.

Ainda se pode observar, simbolicamente, a inclusão dos funcionários na categoria de "companheiros de brinquedo", mencionada por Freyre (2003, p. 149). Nos relatos do autor, os nhonhôs e as senhoras dominavam e faziam de seus serviçais o que desejassem, com certa maldade. De modo semelhante, os sócios, quando se sentem sozinhos em suas esteiras ou precisam inflar seus egos, chamam para perto os estagiários de educação física ou algum funcionário da limpeza que esteja próximo. Sabendo que seria uma quebra do decoro a negação de atenção ao sócio, os funcionários são incluídos em uma conversa. A inclusão na conversa, que tem como temas as viagens, as aquisições e as conquistas desses sócios, exclui o funcionário de uma capacidade econômica e social. Não raro, os mesmos sócios, após seus relatos suntuosos, pedem aos funcionários e estagiários que lhes sirvam um copo de água ou limpem de imediato o equipamento que acabaram de utilizar.

Por fim, a última situação observada ocorreu quando Janaína relatou, com lágrimas nos olhos, que havia pedido demissão do clube, pois teve um ataque de pânico ao ver uma sócia que "pegava em seu pé" subindo para o local em que estava limpando. No entanto, nem no momento em que decidiu sair do clube a humilhação foi afastada. Observa-se nesse caso o que Honneth (2003, p. 217) denomina "denegação das pretensões jurídicas socialmente vigentes" do indivíduo excluído, que causa uma perda de respeito próprio. Janaína passou três dias indo trabalhar com ansiedade e nervosismo, transitando entre o departamento de recursos humanos e os chãos que deveriam estar limpos, pois o clube iria responder, quando o gerente tivesse tempo, se aceitava sua demissão.

Esta última situação relatada foi encarada como um "golpe de misericórdia" aplicado pelo clube em Janaína. Como se não bastasse todo o sofrimento e a humilhação, consciente e inconsciente, por que passava Janaína nos últimos dias de trabalho após pedir sua demissão, que usualmente são aqueles em que o indivíduo está aliviado com sua decisão, ela passou por um último sofrimento, que envolveu estresse e incertezas. Tratava-se de uma demonstração de que não era o clube que a excluía ou incluía nas situações que lhe fossem convenientes, mas toda uma sociedade que é determinada por um grupo hegemônico ao qual ela servia, mas para o qual ela não serve. 


\section{CONSIDERAÇÕES FINAIS: PROJETO ESTRUTURADO DE DESIGUALDADE SOCIAL?}

A observação e apresentação das situações vividas pelos funcionários do clube serviram para percebermos que tais situações não são um acaso, mas um projeto de manutenção e ampliação de desigualdade social. Na introdução deste artigo já deixamos claro que os funcionários são considerados a ralé brasileira, de acordo com a classificação de Souza (2009). Utilizamos, ainda, o tensionamento existente entre os movimentos de exclusão e inclusão para mostrar que não há simplesmente a exclusão social pura, aquela que fora reduzida à pobreza em outros momentos (RAWAL, 2008; AASLAND e FL ØTTEN, 2014). Há aqui, também, a inclusão que marca um indivíduo dentro de um grupo que é excluído em diferentes aspectos, como direitos, cultura e educação, mas que se mostra necessário para a manutenção de determinadas estruturas sociais.

No clube frequentado pelos capatazes da elite (SOUZA, 2017) e localizado na região Sul do Brasil, o funcionário que obtém um cargo operacional também acredita estar acessando um projeto de inclusão social e sente-se parte do clube. Na visão de Sennett (1999), Kuenzer (2002) e Maciel e Grillo (2009), trata-se de um projeto que pega um indivíduo da ralé, dividido entre a iminente possibilidade da delinquência e a entrada no trabalho formal e assalariado, mas precarizado. Os autores defendem que o trabalho é precarizado porque os turnos de trabalho flexíveis oferecidos só são interessantes para o empregador e o funcionário é tratado como um objeto facilmente substituível. Trata-se de uma inclusão com aparência puramente positiva, mas que não revela sua face excludente.

A partir dessa entrada, já não tão includente, uma série de situações que incluem e excluem os indivíduos são vivenciadas. Inicialmente, o funcionário recebe o uniforme que vai marcar ainda mais quem ele é dentro daquele ambiente social. E isso não tem relação com pobreza, corroborando o conceito inicial da exclusão social (RAWAL, 2008; AASLAND e FL $\varnothing$ TTEN, 2014), já que Janaína, mesmo fazendo parte do mais baixo degrau empregatício do clube, possuía bens, casa própria em condomínio fechado e moto. Honesta e trabalhadora, Janaína era sistematicamente vitimizada pela exclusão social e física quando ia almoçar, pela exclusão de dignidade quando, durante 12 horas, ninguém a cumprimentava e pela exclusão de direitos quando ficava 12 horas em pé sem poder sentar, sendo vigiada e não podendo, sequer, ir embora quando pediu sua demissão (HONNETH, 2003).

Também apresentamos o uniforme como evidência de uma forma estruturada de inclusão excludente, já que o sujeito da ralé é incluído em uma condição que lhe poupará de frequentes abordagens policiais (MACIEL e GRILLO, 2009), mas também Ihe marcará como um não consumidor de bons produtos e serviços, como afirmam Celeguim e Roesler (2009) e Souza (2017). A relação entre os funcionários que usam uniforme e aqueles que não usam uniforme é estruturada para legitimar a hierarquia e a desigualdade social entre os grupos. Tal desigualdade também é reproduzida pelos próprios funcionários e membros da ralé, que abaixam suas cabeças quando um sócio passa, e pelos sócios, que só cumprimentam aqueles funcionários com roupas semelhantes às suas - os capatazes da elite.

Pôde-se verificar, ainda, o tensionamento entre exclusão e inclusão tanto nos eventos quanto na função da televisão do clube, quando os produtos e serviços exclusivos são apresentados aos sócios merecedores, mas observados repetidamente pelos membros da ralé. Nesses momentos ocorre aquilo que mencionamos como legitimação, tanto da meritocracia da classe média e de suas conquistas quanto do fracasso da ralé (SOUZA, 2017). Ao passar doze horas observando aqueles bens e serviços, assim como o acesso a eles sendo conquistado por esforço e dedicação, não resta outra opção aos funcionários que não seja trabalhar sem sentar e sem reclamar, para aquilo tudo conquistar. Nesse caso, o funcionário é excluído da capacidade de consumo, mas está incluído em uma situação que pensa ser positiva, pois está trabalhando. Assim, essa inclusão em um trabalho precarizado exclui o trabalhador da possibilidade de aquisição daqueles bens, fazendo com que ele próprio se inclua em um grupo que se percebe como fracassado.

Dessa forma, acreditamos que a pergunta que ensejou este estudo pôde ser respondida ao apresentarmos os símbolos, as formas e as ferramentas que a classe média utiliza para manter e ampliar, sistematicamente, a desigualdade social. Esses recursos, por sua vez, perpassam diferentes formas de exclusão social e inclusão social, conceitos que constatamos, no caso estudado, estar umbilicalmente relacionados. Acreditamos, ainda, que o uso dos conceitos propostos por Kuenzer (2002) se mostrou adequado ao caso empírico e enriqueceu a compreensão dos movimentos realizados e estrategicamente estruturados pela classe média no afastar-se da ralé e no aproximar-se da elite que defende de modo iludido.

Para não deixar este artigo com pontas soltas, concluímos afirmando que, algum tempo depois, Janaína teve, enfim, sua demissão aceita pelo clube. E que a bota "roubada" na epígrafe foi, na verdade, escondida pelas amigas da filha da convidada. Todas saíram rindo da situação após a traquinagem, sem ao menos olhar para o segurança, que voltou em silêncio ao seu posto de trabalho. Ele foi excluído da traquinagem, mas incluído em uma possível bandidagem pelos capatazes da elite. 


\section{REFERÊNCIAS}

AASLAND, A.; FL ØTTEN, T. Ethnicity and social exclusion in Estonia and Latvia. Europe-Asia Studies, v. 53, n. 7, p. 1023-1049, 2014.

BENTHAM, J. O panóptico. 2. ed. Belo Horizonte: Autêntica, 2013.

BENTO, J. A. N. et al. Avaliação multidimensional da exclusão social em áreas rurais. Revista Ciências Administrativas, v. 22, n. 1, p. 306-331, 2016.

BOERE, N.; LIMA, L. Placa em banheiro do Country Club informa que babás não podem entrar. O Globo, Rio de Janeiro, 25 jun. 2016. Disponível em: <https://oglobo.globo.com/rio/placa-em-banheirodo-country-club-informa-que-babas-nao-podem-entrar-19372359>. Acesso em: 16 dez. 2018.

CANNAN, C. The struggle against social exclusion: urban social development in France. IDS Bulletin, v. 28, n. 2, p. 77-85, 1997.

CARNEIRO, M. T.; ROCHA, E. Do fundo do buraco: o drama social das empregadas domésticas. In: SOUZA, J. (Org.). A ralé brasileira: quem é e como vive. Belo Horizonte: Ed. UFMG, 2009. p. 125-142.

CARVALHO-FREITAS, M. N.; MARQUES, A. L. Formas de ver pessoas com deficiência: um estudo empírico do construto de concepções de deficiência em situações de trabalho. Revista de Administração Mackenzie, v. 11, n. 3, p. 100-129, 2010.

CASTEL, R. As metamorfoses da questão social: uma crônica do salário. Petrópolis: Vozes, 1998.

CELEGUIM, C. R. J.; ROESLER, H. M. K. N. A invisibilidade social no âmbito do trabalho. Interação: Revista Científica da Faculdade das Américas, v. 3, n. 1, p. 1-19, 2009.

DEBORD, G. A sociedade do espetáculo. Lisboa: Mobilis in Mobile, 1991.

DJELIC, M. History of management: what is the future for research on the past? In: CZARNIAWSKA, B. (Ed.). A research agenda for management and organization studies. Cheltenham: Edward Elgar, 2016. p. 1-10.

DUARTE, R. Pesquisa qualitativa: reflexões sobre o trabalho de campo. Cadernos de Pesquisa, n. 115, p. 139-154, 2002.

FOOTE-WHYTE, W. Treinando a observação participante. In: GUIMARÃES, A. Z. Desvendando máscaras sociais. Rio de Janeiro: Forense, 1995. p. 77-86.

FOUCAULT, M. Vigiar e punir. 29. ed. Petrópolis: Vozes, 2003.

FREITAS, L.; LUNA, L. A família desorganizada e a reprodução da "ralé estrutural" no Brasil. In: SOUZA, J. (Org.). A invisibilidade da desigualdade brasileira. Belo Horizonte: Ed. UFMG, 2006. p. 323-358.

FREYRE, G. Casa-grande \& senzala: formação da família brasileira sob o regime de economia patriarcal. 48. ed. Recife: Global, 2003.

GONÇALVES, R G. et al. Instrumentos de Planejamento: a interferência nas paisagens urbanas e a exclusão social. Revista Reuna, v. 14, n. 3, 2009.

HAAN, A. Social exclusion: enriching the understanding of deprivation. Studies in social and political thought, v. 2, n. 2, p. 22-40, 2000.
HONNETH, A. Luta por reconhecimento: a gramática moral dos conflitos sociais. São Paulo: Ed. 34, 2003.

JODELET, D. Os processos psicossociais da exclusão. In: SAWAIA, B. (Org.). As artimanhas da exclusão. Petrópolis: Vozes, 1999. p. 53-66.

KUENZER, A. Z. Exclusão includente e inclusão excludente: a nova forma de dualidade estrutural que objetiva as novas relações entre educação e trabalho. Capitalismo, Trabalho e Educação, v. 3, p. 77-96, 2002.

MACIEL, F.; GRILLO, A. O trabalho que (in)dignifica o homem. In: SOUZA, J. (Org.). A ralé brasileira: quem é e como vive. Belo Horizonte: Ed. UFMG, 2009. p. 241-280.

MARTín, M. O dia a dia de uma babá entre a elite do Rio de Janeiro. Pragmatismo Político, João Pessoa, 03 jun. 2016. Disponível em: <https://www.pragmatismopolitico.com.br/2016/06/o-dia-a-diade-uma-baba-entre-a-elite-do-rio-de-janeiro.html>. Acesso em: 16 dez. 2018.

MARTINS, J. S. Sobre o modo capitalista de pensar. 4. ed. São Paulo: Hucitec, 1978.

MARTINS, J. S. Exclusão social e a nova desigualdade. São Paulo: Paulus, 1997.

MARTINS, J. S. Vergonha e decoro na vida cotidiana da metrópole. São Paulo: Hucitec, 1999.

MATITZ, Q. R. S.; VIZEU, F. Construção e uso de conceitos em estudos organizacionais: por uma perspectiva social e histórica. Revista de Administração Pública, Rio de Janeiro, v. 46, n. 2, p. 577-598, 2012.

MEDEIROS, L. F. R.; MACÊDO, K. B. Catador de material reciclável: uma profissão para além da sobrevivência? Psicologia \& Sociedade, v. 18, n. 2, p. 62-71, 2006.

NASCIMENTO, E. P. Hipóteses sobre a nova exclusão social: dos excluídos necessários aos excluídos desnecessários. Caderno CRH, v. 7, n. 21, p. 29-47, 2006.

ORWELL, G. 1984. São Paulo: Companhia das Letras, 2009.

PAULA, A. P. P. et al. A tradição e a autonomia dos estudos organizacionais críticos no Brasil. Revista de Administração de Empresas, v. 50, n. 1, p. 10-23, 2010.

PAUGAM, S. O enfraquecimento e a ruptura dos vínculos sociais. In: SAWAIA, B. (Org.). As artimanhas da exclusão. Petrópolis: Vozes, 1999. p. 67-86.

RAWAL, N. Social inclusion and exclusion: a review. Dhaulagiri Journal of Sociology and Anthropology, v. 2, p. 161-180, 2008.

SAFATLE, V. Só mais um esforço. São Paulo: Três Estrelas, 2017.

SAWAIA, B. (Org.). As artimanhas da exclusão. Petrópolis: Vozes, 1999.

SENNETT, R. A corrosão do caráter. Rio de Janeiro: Record, 1999.

SILVA, D. A.; LIMA, R. A.; NELSON, A. V. M. Exclusão social, ocupação urbana e moradia à luz do princípio da função social das cidades. Interface: Revista do Centro de Ciências Sociais Aplicadas, v. 13, n. 2, p. 129-144, 2016. 
SOUZA, J. (Org.). A ralé brasileira: quem é e como vive. Belo Horizonte: Ed. UFMG, 2009.

SOUZA, J. A elite do atraso: da escravidão à Lava Jato. Rio de Janeiro: Leya, 2017.

SPRADLEY, J. P. The ethnographic interview. Long Grove, IL: Waveland, 2016.
VERAS, M. Exclusão social: um problema brasileiro de 500 anos. In: SAWAIA, B. (Org.). As artimanhas da exclusão: análise psicossocial e ética da desigualdade social. Petrópolis: Vozes, 1999. p. 27-52.

WANDERLEY, M. B. Refletindo sobre a noção de exclusão. In: SAWAIA, B. (Org.). As artimanhas da exclusão. Petrópolis: Vozes, 1999. p. $16-26$

Fernando Ressetti Pinheiro Marques Vianna

ORCID: https://orcid.org/0000-0002-5698-477X

Doutorando em Administração de Empresas pela Escola de Administração de Empresas de São Paulo da Fundação Getulio Vargas (FGV EAESP); Mestre em Administração pela Universidade Tecnológica Federal do Paraná (UTFPR), São Paulo - SP, Brasil. E-mail: fvianna2009@hotmail.com

Francis Kanashiro Meneghetti

ORCID: https://orcid.org/0000-0003-0327-2872

Doutor em Educação e professor na Universidade Tecnológica Federal do Paraná (UTFPR), Curitiba - PR, Brasil.

E-mail: fkmeneghetti@gmail.com

Juliana Previatto Baltini Tonon

ORCID: https://orcid.org/0000-0002-7975-8003

Mestre em Administração; Professora na Faculdade de Ciências Sociais e Aplicadas do Paraná (FACET), Curitiba - PR, Brasil.

E-mail: julianabaldini@yahoo.com.br

Leonardo Tonon

ORCID: https://orcid.org/0000-0002-9884-5284

Doutor em Administração; Professor na Universidade Tecnológica Federal do Paraná (UTFPR), Curitiba - PR, Brasil. E-mail: leonardotonon@utfpr.edu.br 